\title{
Dispersal barriers and stochastic reproductive success do not explain small-scale genetic structure in a broadcast spawning marine mussel
}

\author{
Peter R. Teske ${ }^{1,2,3, *}$, Isabelle Papadopoulos ${ }^{1}$, Nigel P. Barker ${ }^{2}$, Christopher D. McQuaid ${ }^{1}$ \\ ${ }^{1}$ Department of Zoology and Entomology and ${ }^{2}$ Molecular Ecology and Systematics Group, Botany Department, Rhodes University, \\ Grahamstown 6140, South Africa \\ ${ }^{3}$ Molecular Ecology Laboratory, School of Biological Sciences, Flinders University, Adelaide, South Australia 5001, Australia
}

\begin{abstract}
Small-scale genetic heterogeneity in marine broadcast spawners is often attributed either to physical factors that constrain larval dispersal or to stochasticity in reproductive success. In females of the mussel Perna perna, it has been attributed to asymmetrical levels of gene flow between bays and the open coast, with bays acting as sources of propagules. If nearshore currents are an important feature constraining dispersal, then genetic heterogeneity should also be identified in other coastal invertebrates with similar dispersal potential, and the amount of genetic structure in adults and juveniles should be similar, whereas temporal changes in reproductive success should manifest themselves in lower genetic diversity of juveniles. We compared sequence data of female $P$. perna with that of males, juveniles and 3 sympatric marine invertebrates. Congruent genetic structure was only found in a direct developer, suggesting that the region's oceanography does not have a strong structuring effect on species that, like female $P$. perna, have a planktonic dispersal phase. Furthermore, lack of genetic structure in male and juvenile P. perna indicates that there are no physical barriers that reduce larval exchange. Stochastic reproductive success is also an unlikely explanation for genetic structure in $P$. perna because levels of genetic diversity are similar in adults and juveniles. Together with the recent finding that the sex ratio in $P$. perna is skewed toward males, particularly at exposed coastal sites, these results point to a role for selection in driving genetic structure between bays and coastal habitats by eliminating a large proportion of adult females from the open coast.
\end{abstract}

KEY WORDS: Larval dispersal $\cdot$ Marine invertebrate $\cdot$ Cytochrome c oxidase $\cdot$ Sex ratio $\cdot$ Rocky intertidal $\cdot$ Recruitment $\cdot$ Gene flow $\cdot$ Perna perna

\section{INTRODUCTION}

Many marine organisms are broadcast spawners that disperse by means of planktonic propagules, such as gametes, eggs or larvae. It was long believed that the often extended dispersal phase of such species, coupled with very large population sizes and few dispersal barriers in the sea, would result in high levels of connectivity over large geographic scales (Caley et al. 1996, Eckman 1996, Roberts 1997). In recent years, numerous studies have challenged this idea, as genetic structure has been found even at small geographic scales (Jørgensen et al. 2005, Selkoe et al. 2006, Banks et al. 2007, Nicastro et al. 2008, Hogan et al. 2010). In marine invertebrates with sessile adults, genetic structure is usually considered to be the direct result of factors that affect larval dispersal (Johnson \& Black 1984, Hedgecock 1994, Selkoe et al. 2006). These include physical factors, such as the effects of upwelling cells or coastal heterogeneity restricting the transport and settlement of larvae (Hellberg 2009) or resulting in the loss 
of a large proportion of propagules (Gaines \& Bertness 1992), and biological factors, such as stochastic variation in reproductive success that results in relatively few spawning individuals contributing propagules to a particular cohort (so-called 'sweepstakeschance matching'; Hedgecock 1994). Evidence for small-scale environmental variation driving genetic differentiation by selecting against specific genotypes has so far been rarely documented (Johannesson et al. 1995) and is considered unlikely in cases where intraspecific differences of genetic structure in space and time have been documented (Hogan et al. 2010).

In a study comparing genetic structure in female rocky shore mussels Perna perna between several South African coastal sites and bays, Nicastro et al. (2008) identified genetic structure using sequence data from the mitochondrial (mtDNA) cytochrome oxidase c subunit I (COI) gene. Unlike many other species in which genetic structure was found at a scale of tens to several hundred kilometres, the genetic structure in P. perna was by no means characterised by 'chaotic genetic patchiness' (sensu Johnson \& Black 1984) that likely reflects stochasticity in recruitment, but could be linked to coastal topography. While there was no structure between sites on the open coast, sites within bays were genetically distinct not only from those at the coast but also from each other. The observed pattern was attributed to asymmetrical levels of gene flow between bays and the open coast, with bays acting as sources of propagules (Nicastro et al. 2008). As the structuring effects of oceanographic barriers can affect species with different levels of dispersal capability in a similar way (Teske et al. 2007), genetic structure resulting from higher levels of genetic diversity in bays would be expected to be present in at least some sympatric species. Alternatively, sweepstakes-chance matching should manifest itself in lower levels of genetic diversity in new recruits relative to the adult population (Hedgecock 1994).

We tested these hypotheses by comparing the amount of genetic structure and population differentiation in Perna perna with that of 3 similarly abundant coastal invertebrates that occur in the same habitat, two of which are planktonic dispersers, while the third is a direct developer. We also compared genetic data from adults with that of juveniles. Support for neither hypothesis would suggest that presettlement factors, such as high variations in spawning and dispersal of propagules, are insufficient to explain small-scale genetic structure in some broadcast spawners.

\section{MATERIALS AND METHODS}

Samples of juvenile mussels Perna perna, the barnacle Chthamalus dentatus and the limpets Siphonaria capensis and $S$. serrata were collected in Algoa Bay, South Africa, and along the nearby open coast (Fig. 1). Along-coast geographic distances between sites ranged from $22 \mathrm{~km}$ (COAST 1 to BAY 1) for $S$. serrata to $34 \mathrm{~km}$ (COAST 1 to BAY 2) for the other 3 species. The juvenile mussels had a mean $( \pm 1 \mathrm{SD})$ shell length of $25 \pm 3 \mathrm{~mm}$. The barnacle is sessile, and the other 3 species are highly sedentary as adults, although the limpets can forage over distances of $<1 \mathrm{~m}$. Larger-scale dispersal thus takes place by means of planktonic larvae, except in the direct developer $S$. serrata, the juveniles of which hatch fully developed from benthic egg masses and

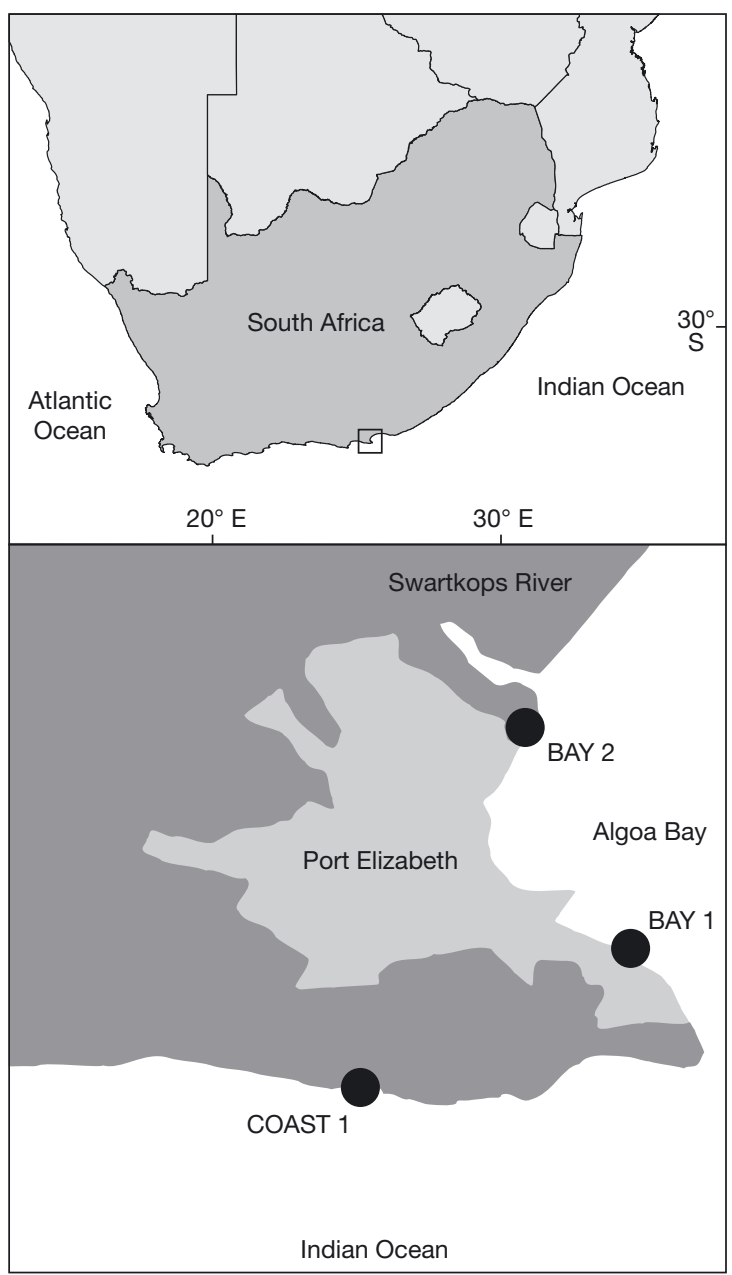

Fig. 1. The sampling area. The upper map shows the location of the sampling area in South Africa. The lower map indicates the location of sampling sites on the open coast (site COAST 1) and in Algoa Bay (BAY 1 and BAY 2) 
remain in the parental habitat. DNA was extracted from foot tissue in the 3 molluscs and from cirri in $C$. dentatus using the CTAB extraction protocol (Doyle \& Doyle 1990). The mitochondrial COI gene was amplified as described previously (Nicastro et al. 2008); it is matrilineally inherited in all 4 species (Weber et al. 2009, Teske et al. 2012). Levels of haplotype and nucleotide diversity were determined in DnaSP v5.10.01 (Librado \& Rozas 2009). To compare genetic diversity in the species with separate sexes ( $P$. perna) with that of hermaphrodites (all others), a data set was created from previously published data (Teske et al. 2012) that combined equal numbers of COI sequences from males and females from each site (Adults $^{\mathrm{a}}$ in Table 1). We also used this data set and a second one (Adults ${ }^{\mathrm{b}}$ in Table 1) in which the number of sequences from male and female mussels reflected empirical sex ratios (coast: 3.8 males:1 female; bay: 1.2 males:1 female; Teske et al. 2012) to compare genetic diversity in adults and juveniles of $P$. perna. The latter could not be sexed due to the absence of gonads. Differences in genetic diversity would support the idea that Hedgecock's (1994) 'sweepstakes-chance matching' may be responsible for genetic heterogeneity in this species. As this hypothesis states that individuals from a particular cohort represent only a fraction of the population's total genetic diversity, there should be a significant difference in diversity between juveniles and adults because the latter represent a large number of different cohorts.

Genetic structure between coastal and bay populations was investigated by calculating $\Phi_{\mathrm{ST}}$ (Michalakis \& Excoffier 1996) and $G_{\text {ST }}^{\prime}$ (Nei 1987) in GenoDive v2.0b20 (Meirmans \& van Tienderen 2004). For the former, a matrix of uncorrected pairwise differences between haplotypes was generated, while the latter is based on haplotype frequencies between populations. The $95 \%$ confidence intervals (95\% CI) were obtained by generating 1000 bootstrap replications over variable positions, and standard errors were based on 1000 permutations. $\Phi_{\mathrm{ST}}$ contains information on evolutionary history and is considered to be the ideal statistic for determining genetic structure from sequence data (Meirmans \& Hedrick 2011). $G_{\text {ST }}^{\prime}$ was calculated to assess statistical power to detect genetic structure for the different data sets, as this is the F-statistic that is used in the simulation program POWSIM v4.1 (Ryman \& Palm 2006; updated version posted July 2011). POWSIM estimates the probability of false negatives (i.e. incorrect acceptance of the null hypothesis of no genetic structure). For each data set, we determined the lowest expected $G_{\text {ST }}^{\prime}$ at which the proportion of $\chi^{2}$ tests at which significant structure $(\mathrm{p}<0.05)$ could be identified was $\geq 0.9$. This was achieved by setting $\mathrm{N}_{\mathrm{e}}$ (effective population size) to 2500 and progressively decreasing $t$ (divergence time) (see POWSIM manual, Appendix 10). A total of 1000 replications were run for each simulation. In cases where $G_{\text {ST }}^{\prime}$ was significant, we also tested for Type I error (incorrect rejection of the null hypothesis of no genetic structure) by setting $t$ to zero.

The data set of Chthamalus dentatus
${ }^{a}$ Equal sex ratio. ${ }^{b}$ Empirical sex ratio (coast: 38 males +14 randomly selected females; bay: 40 males +33 randomly selected females). Diversity estimates for the empirical sex ratio are means from 10 randomly created subsamples 
exceeded the program's maximum of 50 variable sites. Simulations were thus conducted by removing 16 variable sites from the sequences' $3^{\prime}$ ends, and the power reported here is thus a conservative minimum.

The estimation of F-statistics has become controversial because it has often been incorrectly assumed that their magnitude is a strong indicator of gene flow, while it is actually affected by a complex combination of factors (Marko \& Hart 2011). While we made no such assumption in the present study but merely used the F-statistics to compare the previously identified genetic structure in females of Perna perna with that of other data sets, we considered it necessary to confirm the results from the F-statistics with those from an estimator for genetic differentiation between bay and coast populations. To this end, we performed exact tests of population differentiation (Raymond \& Rousset 1995, Goudet et al. 1996) in Arlequin v3.5 (Excoffier \& Lischer 2010). This method tests for non-random distribution of haplotypes between pairs of populations under a hypothesis of panmixia; p-values and their standard deviations were estimated by comparing the observed contingency table with 100000 alternative tables, following 10000 dememorisation steps.
Pairwise estimates of $\Phi_{\text {ST }}$ and $G_{\text {ST }}^{\prime}$ were significant for female Perna perna and for Chthamalus dentatus (Table 2), with the probabilities of Type I errors being zero in both cases. Power simulations indicated that most data sets were sufficiently informative to detect a significant $G_{\text {ST }}^{\prime}$ as low as 0.01 to 0.02 , an exception being the data set of Siphonaria capensis, for which a significant $G_{\text {ST }}^{\prime}$ $\geq 0.05$ could be detected. Given the dependence of p-values on sample size and variability, the magnitude of the F-statistics and their confidence intervals may present a more meaningful way to compare data sets that are not identical in power. Based on confidence intervals, $\Phi_{\mathrm{ST}}$ and $G_{\text {ST }}^{\prime}$ were significantly greater than zero only in female $P$. perna and in the direct developer $S$. serrata (indicating significant genetic structure), and they were greater in female P. perna than in males of the species. $\Phi_{\mathrm{ST}}$ (but not $G_{\mathrm{ST}}^{\prime}$ ) was also significantly greater in adult $P$. perna than in juveniles when equal proportions of adult males and females were specified, but no difference was found when empirical sex ratios were used.

Significant departures from the expectations of panmixia as determined with exact tests of population differentiation were only found in females of Perna perna and in Siphonaria serrata (Table 2).

\section{RESULTS}

A total of 402 new COI sequences were generated, with lengths of 400 (juvenile Perna perna), 432 (Chthamalus dentatus) and 405 (Siphonaria capensis and $S$. serrata) nucleotides. These sequences have been submitted to GenBank (accession numbers KC356872-KC357249). We compared the new sequences with 172 previously published sequences from adult P. perna (Nicastro et al. 2008, Teske et al. 2012). Genetic diversity indices in $P$. perna were mostly larger for the samples from the bay than those from the open coast, with the difference being particularly clear in the adult females (Table 1). Genetic diversity indices for juveniles were not smaller than those for the combined adult data. Greater diversity in the bay was also identified in $S$. capensis (nucleotide diversity) and $S$. serrata (particularly haplotype diversity).
Table 2. Comparison of $\Phi_{\mathrm{ST}}$ values, $G_{\text {ST }}^{\prime}$ values and p-values from exact tests of population differentiation in the mussel Perna perna and 3 other marine invertebrates between Algoa Bay, South Africa, and the adjacent open coast. ${ }^{*} \mathrm{p}<0.05$

\begin{tabular}{|c|c|c|c|}
\hline Species & $\Phi_{\mathrm{ST}} \pm \mathrm{SE}(95 \% \mathrm{CI})$ & $G_{\mathrm{ST}}^{\prime} \pm \mathrm{SE}(95 \% \mathrm{CI})$ & Exact $p$-value $\pm S D$ \\
\hline $\begin{array}{l}\text { Perna perna } \\
\text { (females) }\end{array}$ & $\begin{array}{l}0.031 \pm 0.011^{*} \\
(0.012,0.053)\end{array}$ & $\begin{array}{c}0.028^{\mathrm{c}} \pm 0.010^{*} \\
(0.011,0.048)\end{array}$ & $0.022 \pm 0.006^{*}$ \\
\hline $\begin{array}{r}\text { P. perna } \\
\text { (males) }\end{array}$ & $\begin{array}{c}-0.008 \pm 0.004 \\
(-0.014,-0.001)\end{array}$ & $\begin{array}{l}-0.008^{\mathrm{d}} \pm 0.004 \\
(-0.014,-0.001)\end{array}$ & $0.185 \pm 0.005$ \\
\hline $\begin{array}{l}\text { P. perna } \\
\text { (adults) }^{\mathrm{a}}\end{array}$ & $\begin{array}{c}0.002 \pm 0.002 \\
(-0.001,0.006)\end{array}$ & $\begin{array}{l}0.002^{\mathrm{d}} \pm 0.002 \\
(-0.001,0.007)\end{array}$ & $0.122 \pm 0.017$ \\
\hline $\begin{array}{l}\text { P. perna } \\
\text { (adults) }^{\mathrm{b}}\end{array}$ & $\begin{array}{l}-0.004 \pm 0.002 \\
(-0.007,0.008)\end{array}$ & $\begin{array}{c}-0.001^{\mathrm{d}} \pm 0.003 \\
(-0.006,0.004)\end{array}$ & $0.270 \pm 0.017$ \\
\hline $\begin{array}{l}P . \text { perna } \\
\text { (juveniles) }\end{array}$ & $\begin{array}{c}-0.009 \pm 0.001 \\
(-0.010,-0.006)\end{array}$ & $\begin{array}{c}-0.003^{\mathrm{d}} \pm 0.003 \\
(-0.008,0.003)\end{array}$ & $0.720 \pm 0.026$ \\
\hline $\begin{array}{l}\text { Chthamalus } \\
\text { dentatus }\end{array}$ & $\begin{array}{c}0.019 \pm 0.100^{*} \\
(0.000,0.037)\end{array}$ & $\begin{array}{c}0.019^{\mathrm{d}} \pm 0.010^{*} \\
(0.000,0.038)\end{array}$ & $0.348 \pm 0.011$ \\
\hline $\begin{array}{l}\text { Siphonaria } \\
\text { Capensis }\end{array}$ & $\begin{array}{l}-0.004 \pm 0.011 \\
(-0.018,0.012)\end{array}$ & $\begin{array}{l}-0.004^{\mathrm{e}} \pm 0.01 \\
(-0.018,0.011)\end{array}$ & $0.900 \pm 0.008$ \\
\hline S. serrata & $\begin{array}{l}0.010 \pm 0.005 \\
(0.004,0.027)\end{array}$ & $\begin{array}{l}0.010^{\mathrm{c}} \pm 0.005 \\
(0.004,0.026)\end{array}$ & $0.008 \pm 0.003^{*}$ \\
\hline \multicolumn{4}{|c|}{$\begin{array}{l}{ }^{\mathrm{a}} \text { Even sex ratio for adult } P \text {. perna. }{ }^{\mathrm{b}} \text { Composition of sequences reflected } \\
\text { empirical sex ratio; all values reported for the latter are means from } 10 \text { sub- } \\
\text { samples from which sequences of } 24 \text { coastal and } 7 \text { bay females had been } \\
\text { randomly removed. }{ }^{\mathrm{c}, \mathrm{d}, \mathrm{e} \text { Lowest }} G_{\mathrm{ST}} \text { that can be identified as being signifi- } \\
\text { cant based on power analyses: }{ }^{\mathrm{c}} 0.02,{ }^{\mathrm{d}} 0.01,{ }^{\mathrm{e}} 0.05\end{array}$} \\
\hline
\end{tabular}




\section{DISCUSSION}

In the present study, we identified significant small-scale genetic structure in 2 out of 4 marine invertebrates between a South African bay and the nearby open coast. Genetic heterogeneity at a scale of $10 \mathrm{~s}$ to several $100 \mathrm{~s}$ of kilometres has been explained by 3 hypotheses (Larson \& Julian 1999): variation in the source of larvae due to physical oceanographic constraints that prevent extensive mixing between larvae from different sources, 'sweepstakes-chance matching' (Hedgecock 1994) and preor post-settlement selection. As each hypothesis makes some very specific assumptions about how the mechanisms invoked manifest themselves in patterns of genetic diversity, it is possible to contrast their relative merits in explaining the patterns observed here.

Oceanographic barriers that prevent extensive mixing of propagules from different regions are often invoked at larger geographic scales (several 100s to 1000s of kilometres) and may include upwelling cells (Waters \& Roy 2004), long stretches of unsuitable habitat (Teske et al. 2006, Ayre et al. 2009) and areas where currents are deflected away from the coast and potentially displace propagules that become entrained in them (Teske et al. 2011, Zardi et al. 2011). The populations identified at these scales tend to exhibit evidence of genetic divergence that may be a function of long-term reductions in gene flow and/or divergent selection driven by environmental gradients (Teske et al. 2011). Levels of gene flow among them can be estimated using coalescent samplers, which provide better estimates of connectivity than $F$-statistics because they take into consideration the evolutionary histories and effective population sizes of the populations (Marko \& Hart 2011). At smaller geographic scales and in the absence of strong oceanographic barriers, populations tend to exhibit lower levels of differentiation (Teske et al. 2007) that merely manifest themselves in allele frequency differences (Johnson \& Black 1984, Nicastro et al. 2008). We attempted to estimate levels of gene flow among bay and coast populations using the coalescent samplers MIGRATE-N v3.2 (Beerli 2009) and IMa2 (Hey 2010), but neither method produced usable results for any of the data sets (i.e. likelihood curves did not return to zero after reaching a peak, increased indefinitely irrespective of how high the upper margin was set or had no clearly defined peak or multiple peaks). The main reason for this is unlikely to be the use of a single locus, as previous studies using only COI sequences have produced usable results (e.g. Teske et al. 2007), but rather that the programs' model assumption that several distinct evolutionary lineages are present was violated.

Several studies that have identified small-scale genetic structure but found no evidence for distinct evolutionary lineages have nonetheless invoked putative oceanographic barriers, such as upwelling cells and coastal heterogeneity, as factors that drive genetic differentiation (Hellberg 2009). If such mechanisms were important in the study area, then they could be expected to have created congruent patterns of genetic diversity in at least some of the species studied, with genetic diversity indices being higher in the bay because of highly asymmetrical levels of gene flow (Nicastro et al. 2008). We found significant genetic structure only in female Perna perna and in the barnacle Chthamalus dentatus. In the latter, this result is problematic because, while the $\Phi_{\mathrm{ST}}$ value of 0.19 is comparatively high, it has a large $95 \%$ confidence interval that includes zero. In contrast, the $\Phi_{\mathrm{ST}}$ value estimated for the direct developer Siphonaria serrata was significantly greater than zero, and based on exact tests of population differentiation, the data set of $S$. serrata was the only one apart from that of the females of P. perna where a significant departure from the expectations of panmixia was found. Although direct developers can show a surprising degree of dispersion and can rapidly colonise new habitats through rafting of egg masses or adults (e.g. Johannesson \& Warmoes 1990), in this species, genetic structure and significant population differentiation are more likely the result of juveniles remaining in the parental habitat. Genetic heterogeneity in female P. perna is thus likely to be the result of a different mechanism than that in S. serrata. Support for the hypothesis that genetic heterogeneity is driven by dispersal barriers is further weakened by the fact that the males of $P$. perna (which carry the mitochondrial genome of females from the previous generation) were not genetically structured. While it is possible that sexspecific differences in larval behaviour have resulted in dispersal barriers affecting male and female larvae differently, the fact that mytilid mussel larvae disperse like passive particles and their dispersal can thus be readily predicted using information about sea-surface currents (McQuaid \& Philips 2000) suggests that this is very unlikely.

The 'sweepstakes-chance matching' hypothesis by Hedgecock (1994) is often invoked to explain the chaotic genetic patchiness observed at small scales in many marine invertebrates with potentially high dispersal ability. Hedgecock (1994) suggested that 
genetic variation of recruits might be the result of large variance in the reproductive success of adults, with a particular cohort being the offspring of a relatively small portion of the adult population. As this amounts to a genetic bottleneck in the cohort, a particular year class would be expected to have a lower genetic diversity than the adult population. The fact that adult populations at different sites represent different combinations of such cohorts would explain the existence of genetically distinct populations at each site. As genetic diversity indices for juvenile Perna perna were not lower than those estimated for adults, there is no support for this hypothesis in this species. In the barnacle Chthamalus dentatus, coast and bay populations had identical genetic diversity, and potential genetic structure in this species clearly has a different cause from that in female P. perna. The inclusion of additional sites and different age cohorts is required to determine whether sweepstakes-chance matching drives genetic divergence in C. dentatus.

Given the scant support for the first 2 hypotheses, we conclude that selection may play a role in driving and maintaining genetic structure in Perna perna. Multilocus data generated using next-generation sequencing technology have shown that even in species with very high dispersal potential, outlier loci that show signatures of divergent selection can be present in populations inhabiting environmentally distinct habitats (e.g. Limborg et al. 2012), and similar results have been found by studying phenotypic traits (Hice et al. 2012). Without such data, we can only speculate on how environmental conditions may drive and maintain genetic struture in P. perna, but information on the species' biology and ecology can provide some clues.

We have previously suggested that the skewed sex ratio in Perna perna could be the result of post-settlement selection (Teske et al. 2012). Females have greater reproductive output than males (Zardi et al. 2007), and mussels in bays produce more gametes than those on the open coast (McQuaid \& Phillips 2006). While no relationship between reproductive output and attachment strength was found in bays, a negative correlation was found on the open coast, suggesting that increasing energy allocation to attachment strength as a response to intensified wave action negatively affects gonad tissue development (Nicastro et al. 2010). Theoretically, selection would favour females that channel more energy into reproduction in bays (where wave action is less severe) and females that favour attachment over reproduction on the open coast (where wave action is more severe), so it is possible that the skewed sex ratio on the open coast could be the result of females whose mothers resided in the bay expending too much energy on reproduction and too little on attachment. This could result in a large proportion of females that are the offspring of bay individuals being eliminated from exposed open coast shores during each generation, resulting in the observed lower genetic diversity on the coast and sex-specific genetic structure between habitats. Nicastro et al. (2010) did not find any relationship between wave action and mortality, with the exception of a single event in which a sudden increase in hydrodynamic stress, coupled with sand inundation, followed a major spawning event, which may not have allowed a large proportion of the mussels to channel sufficient energy into increasing their attachment strength in time. In measuring attachment strength, Nicastro et al. (2010) did not differentiate between males and females, and any correlation between wave action and mortality would have been further reduced if females originating from bays were eliminated during early adulthood, making them less abundant on the open coast.

The possibility that the skewed sex ratio on the open coast already exists prior to adulthood can nonetheless not be ruled out. The $\Phi_{\mathrm{ST}}$ value estimated between the bay and coast for a data set of COI sequences from adults in which the skewed sex ratio was incorporated was not significantly different from the $\Phi_{\mathrm{ST}}$ value estimated for juveniles, whereas the $\Phi_{\mathrm{ST}}$ based on equal sex ratios was significantly greater. In mytilid mussels with doubly uniparental inheritance of mtDNA in which both a maternal and a paternal mitochondrial genome is present, skewed sex ratios have been reported in the offspring (Saavedra et al. 1997, Kenchington et al. 2002). However, even if this applies in Perna perna, it cannot fully explain the highly skewed sex ratio on the open coast, as the sex ratio in bays is almost even. Any preor post-settlement selection must therefore be the result of challenging environmental conditions on the open coast.

\section{CONCLUSION}

In the present study, we found no strong support for 2 commonly invoked pre-settlement factors that could explain small-scale genetic structure within coastal regions. Genetic heterogeneity in female Perna perna could not be explained by nearshore circulation resulting in asymmetrical dispersal, nor did 
we find evidence for temporal changes in population structure resulting from chance mating success. While we cannot explain the mechanism that has driven genetic structure in female P. perna, our study points to a role for species- and gender-specific adaptive constraints in driving genetic structure. Selection is rarely invoked as an explanation for genetic heterogeneity in studies of this nature, but this may be partly due to the fact that it is difficult to demonstrate conclusively. Recent technological advances in genomics have, however, made this more feasible, and we hope that our study will stimulate further research into elucidating how adaptive constraints can result in small-scale genetic patterns like the one observed in female $P$. perna.

Acknowledgements. This work was supported by a grant from the South African Research Chairs Initiative (SARChI) of the Department of Science and Technology and the National Research Foundation (NRF) to C.D.M., and by grant no. 206119 from the NRF to N.P.B. P.R.T. was supported by a postdoctoral research fellowship from Rhodes University and by Flinders University. This contribution represents publication no. 42 of the Molecular Ecology Group for Marine Research (MEGMAR) at Flinders University.

\section{LITERATURE CITED}

Ayre DJ, Minchinton TE, Perrin C (2009) Does life history predict past and current connectivity for rocky intertidal invertebrates across a marine biogeographic barrier? Mol Ecol 18:1887-1903

Banks SC, Piggott MP, Williamson JE, Bove U, Holbrook NJ, Beheregaray LB (2007) Oceanic variability and coastal topography shape local genetic structure in a long-dispersing marine invertebrate. Ecology 88:3055-3064

Beerli P (2009) How to use MIGRATE or why are Markov chain Monte Carlo programs difficult to use? In: Bertorelle G, Bruford MW, Hauïe HC, Rizzoli A, Vernesi C (eds) Population genetics for animal conservation. Cambridge University Press, Cambridge, p 42-79

Caley MJ, Carr MH, Hixon MA, Hughes TP, Jones GP, Menge BA (1996) Recruitment and the local dynamics of open marine populations. Annu Rev Ecol Syst 27: 477-500

Doyle JJ, Doyle JL (1990) Isolation of plant DNA from fresh tissue. Focus 12:13-15

> Eckman JE (1996) Closing the larval loop: linking larval ecology to the population dynamics of marine benthic invertebrates. J Exp Mar Biol Ecol 200:207-237

> Excoffier L, Lischer HEL (2010) Arlequin suite ver 3.5: a new series of programs to perform population genetics analyses under Linux and Windows. Mol Ecol Res 10:564-567

Gaines SD, Bertness MD (1992) Dispersal of juveniles and variable recruitment in sessile marine species. Nature 360:579-580

Goudet J, Raymond M, de Meeüs T, Rousset F (1996) Testing differentiation in diploid populations. Genetics 144:1933-1940

Hedgecock D (1994) Temporal and spatial genetic structure of marine animal populations in the California current. CalCOFI Report 35:73-81

Hellberg ME (2009) Gene flow and isolation among populations of marine animals. Annu Rev Ecol Evol Syst 40: 291-310

Hey J (2010) Isolation with migration models for more than two populations. Mol Biol Evol 27:905-920

Hice LA, Duffy TA, Munch SB, Conover DO (2012) Spatial scale and divergent patterns of variation in adapted traits in the ocean. Ecol Lett 15:568-575

Hogan JD, Thiessen RJ, Heath DD (2010) Variability in connectivity indicated by chaotic genetic patchiness within and among populations of a marine fish. Mar Ecol Prog Ser 417:263-275

> Johannesson K, Warmoes T (1990) Rapid colonization of Belgian breakwaters by the direct developer, Littorina saxatilis (Olivi) (Prosobranchia, Mollusca). Hydrobiologia 193:99-108

> Johannesson K, Johannesson B, Lundgren U (1995) Strong natural selection causes microscale allozyme variation in a marine snail. Proc Natl Acad Sci USA 92:2602-2606

Johnson MS, Black R (1984) Pattern beneath the chaos: the effect of recruitment on genetic patchiness in an intertidal limpet. Evolution 38:1371-1383

> Jørgensen HBH, Hansen MM, Bekkevold D, Ruzzante DE, Loeschcke V (2005) Marine landscapes and population genetic structure of herring (Clupea harengus L.) in the Baltic Sea. Mol Ecol 14:3219-3234

Kenchington E, MacDonald B, Cao L, Tsagkarakis D, Zouros E (2002) Genetics of mother-dependent sex ratio in blue mussels (Mytilus spp.) and implications for doubly uniparental inheritance of mitochondrial DNA. Genetics 161:1579-1588

Larson RJ, Julian RM (1999) Spatial and temporal genetic patchiness in marine populations and their implications for fisheries management. CalCOFI Report 40:94-99

> Librado P, Rozas J (2009) DnaSP v5: a software for comprehensive analysis of DNA polymorphism data. Bioinformatics 25:1451-1452

> Limborg MT, Helyar SJ, de Bruyn M, Taylor MI and others (2012) Environmental selection on transcriptomederived SNPs in a high gene flow marine fish, the Atlantic herring (Clupea harengus). Mol Ecol 21: 3686-3703

> Marko PB, Hart MW (2011) The complex analytical landscape of gene flow inference. Trends Ecol Evol 26: 448-456

> McQuaid CD, Philips TE (2000) Limited wind-driven dispersal of intertidal mussel larvae: in situ evidence from the plankton and the spread of the invasive species Mytilus galloprovincialis in South Africa. Mar Ecol Prog Ser 201: 211-220

> McQuaid CD, Phillips TE (2006) Mesoscale variation in reproduction, recruitment and population structure of intertidal mussels with low larval input: a bay/open coast comparison. Mar Ecol Prog Ser 327:193-206

Meirmans PG, Hedrick PW (2011) Assessing population structure: $F_{\mathrm{ST}}$ and related measures. Mol Ecol Res 11: $5-18$

> Meirmans PG, van Tienderen PH (2004) GENOTYPE and GENODIVE: two programs for the analysis of genetic diversity of asexual organisms. Mol Ecol Notes 4: 792-794

Michalakis Y, Excoffier L (1996) A generic estimation of population subdivision using distances between alleles 
with special reference for microsatellite loci. Genetics 142:1061-1064

Nei M (1987) Molecular Evolutionary Genetics. Columbia University Press, New York, NY

- Nicastro KR, Zardi GI, McQuaid CD, Teske PR, Barker NP (2008) Coastal topography drives genetic structure in marine mussels. Mar Ecol Prog Ser 368:189-195

Nicastro KR, Zardi GI, McQuaid CD (2010) Differential reproductive investment, attachment strength and mortality of invasive and indigenous mussels across heterogeneous environments. Biol Inv 12:2165-2177

Raymond M, Rousset F (1995) An exact test for population differentiation. Evolution 49:1280-1283

Roberts CM (1997) Connectivity and management of Caribbean coral reefs. Science 278:1454-1457

Ryman N, Palm S (2006) POWSIM: a computer program for assessing statistical power when testing for genetic differentiation. Mol Ecol 6:600-602

Saavedra C, Reyero MI, Zouros E (1997) Male-dependent doubly uniparental inheritance of mitochondrial DNA and female-dependent sex-ratio in the mussel Mytilus galloprovincialis. Genetics 145:1073-1082

Selkoe KA, Gaines SD, Caselle JE, Warner RR (2006) Current shifts and kin aggregation explain genetic patchiness in fish recruits. Ecology 87:3082-3094

Teske PR, McQuaid CD, Froneman PW, Barker NP (2006) Impacts of marine biogeographic boundaries on phylogeographic patterns of three South African estuarine crustaceans. Mar Ecol Prog Ser 314:283-293

Teske PR, Papadopoulos I, Zardi GI, McQuaid CD, Edkins

Editorial responsibility: Roger Hughes,

Bangor, UK
MT, Griffiths CL, Barker NP (2007) Implications of life history for genetic structure and migration rates of southern African coastal invertebrates: planktonic, abbreviated and direct developers. Mar Biol 152:697-711

Teske PR, Papadopoulos I, Mmonwa KL, Matumba TG, McQuaid CD, Barker NP, Beheregaray LB (2011) Climate-driven genetic divergence of limpets with different life histories across a southeast African marine biogeographic disjunction: different processes, same outcome. Mol Ecol 20:5025-5041

Teske PR, Papadopoulos I, Barker NP, McQuaid CD (2012) Mitochondrial DNA paradox: sex-specific genetic structure in a marine mussel-despite maternal inheritance and passive dispersal. BMC Genet 13:45

> Waters JM, Roy MS (2004) Phylogeography of a high-dispersal New Zealand sea-star: Does upwelling block geneflow? Mol Ecol 13:2797-2806

Weber LI, Hildebrand CG, Clezar C (2009) No evidence of doubly uniparental inheritance in the brown mussel Perna perna from the RFLP analyses of the mitochondrial 16S rDNA. Braz J Aquat Sci Technol 13:51-57

> Zardi GI, McQuaid CD, Nicastro KR (2007) Balancing survival and reproduction: seasonality of wave action, attachment strength and reproductive output in indigenous Perna perna and invasive Mytilus galloprovincialis mussels. Mar Ecol Prog Ser 334:155-163

- Zardi GI, Nicastro KR, McQuaid CD, Hancke L, Helmuth B (2011) The combination of dispersal and selection helps explain genetic structure in intertidal mussels. Oecologia 165:947-958

Submitted: August 10, 2012; Accepted: December 17, 2012 Proofs received from author(s): March 29, 2013 